\title{
SIZE OPTIMIZATION OF RECTANGULAR CROSS-SECTION MEMBERS SUBJECT TO FATIGUE CONSTRAINTS
}

\author{
Juan M. González Mendoza, Samuel Alcántara Montes \\ Department of Graduate Studies and Research, National Polytechnic Institute, Mexico \\ e-mail: johann009@yahoo.com; sammotion@yahoo.com.mx \\ José De J. Silva Lomelí, Juan A. Flores Campos \\ UPIITA, National Polytechnic Institute, Mexico; e-mail: jsilval@ipn.mx; jaflores@ipn.mx
}

\begin{abstract}
Although in the scientific literature there are studies regarding optimization of structural members subject to static loads or even cyclic in-phase loads, the optimization of structures subject to cyclic, out-of-phase multiaxial loads is still an unexplored issue. In this paper, we present an approach to the problem of size optimization of rectangular cross-section members subject to multiaxial in-phase and out-of-phase cyclic loads. The objective of the optimization is to minimize the cross sectional area of such elements while retaining their fatigue endurance. Under the proposed methodology, optimum values of the area are achieved for six loading cases and for three values of the height to width ratio of the cross section, and these values are reported. The novelty of the approach lies in the inclusion of two multiaxial high cycle fatigue criteria, i.e., Dang Van and Vu-Halm-Nadot ones, as constraints for size optimization problems, fully integrated within an in-house developed tool, capable of handling non-proportional stresses. A plot of the feasible solution space for this optimization problem is also obtained.
\end{abstract}

Keywords: size optimization, multiaxial fatigue, non-proportional

\section{Nomenclature}

$\begin{array}{ll}u_{1}, u_{2} & - \text { design variables } \\ M_{t}, M_{b} & - \text { applied torsional and bending moment, respectively } \\ f_{-1}, t_{-1} & - \text { fatigue limit in fully reversed bending and torsion, respectively } \\ S_{u} & - \text { ultimate strength } \\ \sigma_{i j} & - \text { macroscopic stress tensor } \\ \sigma_{H} & - \text { hydrostatic stress } \\ S_{i j}, s_{i j} & - \text { macroscopic and mesoscopic deviatoric stress tensor, respectively } \\ \text { dev } \rho_{i j}^{*} & - \text { deviatoric local residual stress tensor } \\ I_{1 a}, I_{1 m} & - \text { amplitude and mean value of first invariant of stress tensor, respectively } \\ J_{2 a} & - \text { amplitude of second invariant of deviatoric stress tensor } \\ \phi & - \text { phase angle }\end{array}$

\section{Introduction}

Optimization of structural elements is an important problem in engineering design, and rectangular cross-section members are widely used in engineering applications for machine components.

Many authors have applied size, shape and topology optimization techniques to structural elements as diverse as beams, test specimens, or notched elements subject generally to static loads or proportional cyclic loads. 
Baptista et al. (2014) optimized the geometry of cruciform specimens for biaxial fatigue testing machines in order to obtain maximum and uniform stress values in the gauge area of such specimens, where the fatigue damage was supposed to initiate. Ghelichi et al. (2011) optimized the shape of the notches in components subject to multiaxial cyclic loads using the Liu-Zenner criterion and decreasing the stress concentration at the notch.

Andjelić and Milosević-Mitić (2012) solved the problem of optimization of thin walled I-beams loaded in static bending and torsion. They determined the minimum mass of the I-beam subject to stress constraints.

Mrzygłód (2010) and Mrzygłód and Zieliński (2006) made remarkable contributions by implementing multiaxial, high cycle fatigue criteria as constraints in the structural optimization of vehicle parts on the assumption of in-phase loadings. The goal of their optimization was to decrease the mass of the parts while retaining their fatigue endurance.

Holmberg et al. (2014) explored the problem of topology optimization with fatigue constraints. Their objective was to find the design with the minimum mass that could still withstand a specific life time. They tested their methodology with some examples involving only one load direction on models such as L-shaped beams.

Jeong et al. (2015) should be mentioned for developing a topology optimization method that included static stress and fatigue constraints, the aim of which was to minimize the mass of structures under the effect of constant amplitude proportional loads. They proved the applicability of their approach to two-dimensional continuum structures.

In the experimental field, the work by Rozumek et al. (2010) has to be noticed as they conducted tests on rectangular cross-section specimens subject to combined cyclic loadings and recorded their lives to crack initiation.

However, there is little research related to the optimization of structural elements subject to fatigue constraints, much less multiaxial fatigue constraints for problems involving in-phase as well as out-of-phase cyclic loads.

Therefore, the main problem to be addressed in this paper is to present an approach to the size optimization of structural members including multiaxial fatigue criteria as constraints, when the structural member under consideration is subject to biaxial proportional and nonproportional loads, using in-house developed tools.

\section{Description of geometry, stresses and loads applied}

The objective of the optimization is to minimize the area of rectangular cross-section members subject to biaxial cyclic loading, i.e., combined in-phase and out-of-phase bending with torsion while retaining their fatigue endurance. Therefore, it is necessary to analyze briefly the relationships between the loads being applied to such members and the resulting normal and shear stresses.

Let us consider a rectangular cross-section member subject to a torsional moment as well as to a bending moment as shown in Fig. 1. The maximum shear stress at the center of the long side due to the torsional moment is given by equation (2.1) 1 (Boresi, 2002). Meanwhile, the stress on the short side is given by equation $(2.1)_{2}$, point $A$. In Fig. 1 , as in the optimization process, the width and height of the cross section are identified as $u_{1}, u_{2}$, respectively

$$
\tau_{\max }=\sigma_{13}=\frac{M_{t}}{k_{2} u_{2} u_{1}^{2}} \quad \sigma_{12}=k_{3} \tau_{\max }
$$

Factors $k_{2}, k_{3}$ are shown in Table 1 for several values of the height to width ratio $u_{2} / u_{1}$ assuming the case where $u_{2}>u_{1}$. 
(a) $X_{3} \uparrow$

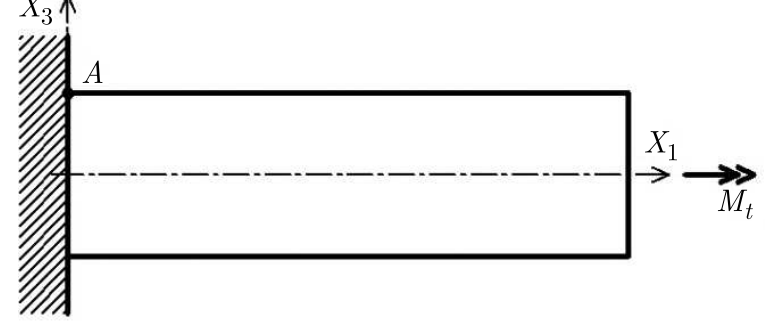

(b)

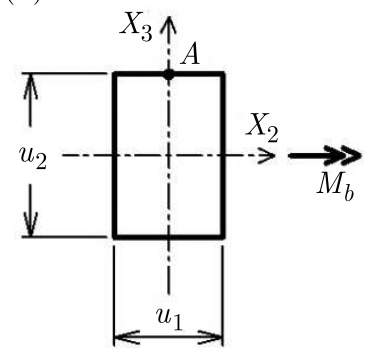

Fig. 1. Rectangular cross-section cantilever beam subjected to combined bending with torsion: (a) left view, applied torsional moment, (b) front view, applied bending moment

Table 1. Factors $k_{2}, k_{3}$. Data from Timoshenko and Goodier (1951) and from Gasiak and Robak (2010)

\begin{tabular}{|c|c|c|c|c|c|c|c|}
\hline$u_{2} / u_{1}$ & 1.0 & 1.5 & 2.0 & 3.0 & 4.0 & 6.0 & 10.0 \\
\hline$k_{2}$ & 0.208 & 0.231 & 0.246 & 0.267 & 0.282 & 0.299 & 0.312 \\
\hline$k_{3}$ & 1.000 & 0.859 & 0.795 & 0.753 & 0.745 & 0.743 & 0.742 \\
\hline
\end{tabular}

With regard to the normal stress, owing to the bending moment, it reaches its maximum value at point $A$ calculated using equation

$$
\sigma_{11}=\frac{6 M_{b}}{u_{1} u_{2}^{2}}
$$

We consider the normal and shear stresses at point $A$ and also make the following assumptions:

- Bending and torsional moments are applied in a cyclic, fully reversible manner, under the high cycle fatigue regime.

- With loads applied in a synchronous and sinusoidal way, the normal and shear stresses change along one loading cycle according to equations

$$
\sigma_{11}(t)=\sigma_{11, m}+\sigma_{11, a} \sin \frac{2 \pi t}{T} \quad \sigma_{12}(t)=\sigma_{12, m}+\sigma_{12, a} \sin \left(\frac{2 \pi t}{T}-\phi\right)
$$

\section{Fatigue criteria included as constraints}

The fatigue criteria selected to be included as constraints, i.e., Dang Van, Vu-Halm-Nadot ones, show good agreement with experimental results. They have been selected such that a comparative base for the obtained results can be established with the fatigue criteria based on different methods, i.e., a multi-scale method or stress invariant method.

Although further explanation of these criteria can be found respectively in (Dang Van et al., 1989; Vu et al., 2010), we make a short review of the stresses to be calculated for each of them.

\subsection{Dang Van criterion}

This criterion evaluates an equivalent stress resulting from the linear combination of mesoscopic shear and hydrostatic stresses. Then it compares this equivalent stress against the fatigue limit in fully reversed torsion $t_{-1}$, see equation $(3.3)_{1}$. As a previous step to the calculation 
of mesoscopic stresses, it is mandatory to obtain quantities such as components of the macroscopic stress tensor $\sigma_{i j}(t)$, the hydrostatic stress $\sigma_{H}(t)$, and the macroscopic deviatoric stress tensor $S_{i j}(t)$ all of them acting throughout one loading cycle

$$
\sigma_{H}(t)=\frac{\sigma_{1}(t)+\sigma_{2}(t)+\sigma_{3}(t)}{3} \quad S_{i j}(t)=\sigma_{i j}(t)-\sigma_{H}(t) I_{i j}
$$

The calculation of the deviatoric local residual stress tensor $\operatorname{dev} \rho_{i j}^{*}$, is not a trivial task when loads are non-proportional, but it is a fundamental step to the calculation of mesoscopic stresses

$$
s_{i j}(t)=S_{i j}(t)+\operatorname{dev} \rho_{i j}^{*} \quad \tau(t)=\frac{s_{1}(t)-s_{3}(t)}{2}
$$

The value of $\bar{\alpha}$ is defined in equation $(3.3)_{2}$, and for both criteria $\bar{\beta}=t_{-1}$

$$
\max \left[\tau(t)+\bar{\alpha} \sigma_{H}(t)\right] \leqslant \bar{\beta} \quad \bar{\alpha}=\frac{3 t_{-1}}{f_{-1}}-\frac{3}{2}
$$

\subsection{Vu-Halm-Nadot criterion}

This multiaxial fatigue criterion is based on invariants of the macroscopic stress tensor and it has an advantage of low-computation time. Its evaluation requires, in the first place, calculation of the amplitude of the second invariant of the macroscopic deviatoric stress tensor

$$
J_{2}^{\prime}(t)=\sqrt{J_{2 a}(t)}=\sqrt{\frac{1}{2}\left[S_{a}(t) \cdot S_{a}(t)\right]}
$$

after which their authors propose to introduce the mean value of the second invariant of the deviatoric stress tensor along one loading cycle

$$
J_{2, \text { mean }}=\frac{1}{T} \int_{0}^{T} J_{2}^{\prime}(t) d t
$$

Once these quantities are obtained, the Vu-Halm-Nadot criterion is expressed as

$$
\sqrt{\gamma_{1} J_{2}^{\prime 2}(t)+\gamma_{2} J_{2, \text { mean }}^{2}+\gamma_{3} I_{f}\left(I_{1 a}, I_{1 m}\right)} \leqslant \bar{\beta}
$$

where $I_{f}$ is a function of $I_{1 a}$ and $I_{1 m}$

$$
\begin{aligned}
& I_{1 a}=\frac{1}{2}\left\{\max _{t \in T} I_{1}(t)-\min _{t \in T} I_{1}(t)\right\} \\
& I_{1 m}=\frac{1}{2}\left\{\max _{t \in T} I_{1}(t)+\min _{t \in T} I_{1}(t)\right\}
\end{aligned}
$$

While using this criterion, the ultimate strength is employed to distinguish between two classes of metals, i.e., low-strength with $S_{u}<750 \mathrm{MPa}$, and for which $I_{f}$ is given by

$$
I_{f}\left(I_{1 a}, I_{1 m}\right)=I_{1 a}+I_{1 m}
$$

and high-strength with $S_{u}>750 \mathrm{MPa}$, and for which $I_{f}$ is given by

$$
I_{f}\left(I_{1 a}, I_{1 m}\right)=I_{1 a}+\frac{f_{-1}}{t_{-1}} I_{1 m}
$$

where $\gamma_{1}, \gamma_{2}$ are material parameters dependent on the ultimate strength of the material. The value of $\gamma_{3}$ is given by

$$
\gamma_{3}=\frac{1}{f_{-1}}\left(t_{-1}^{2}-\frac{f_{-1}^{2}}{3}\right)
$$


For low-strength metals: $\gamma_{1}=0.65, \gamma_{2}=0.8636$; for high-strength metals: $\gamma_{1}=0.3, \gamma_{2}=1.7272$.

An in-house tool has been developed for the use of such criteria as fatigue constraints on size optimization problems for both proportional and non-proportional loads. This in-house tool has been developed using the commercial software Matlab (MATLAB Optimization Toolbox User's Guide, 2013).

\section{Formulation of the optimization problem}

The size optimization problem can be expressed as finding the set of design variables $\{u\}$ that minimize the objective function, i.e., the area of the rectangular cross-section members subject to biaxial bending with torsion

$$
\min f\left(u_{1}, u_{2}\right)=u_{1} u_{2}
$$

while keeping the state variable, i.e., their fatigue endurance under the value of $\bar{\beta}$ (Christensen and Klarbring, 2009), selecting one of the equations

$$
\begin{aligned}
& \max \left[\tau(t)+\bar{\alpha} \sigma_{H}(t)\right] \leqslant \bar{\beta} \\
& \sqrt{\gamma_{1} J_{2}^{\prime 2}(t)+\gamma_{2} J_{2, \text { mean }}^{2}+\gamma_{3} I_{f}\left(I_{1 a}, I_{1 m}\right)} \leqslant \bar{\beta}
\end{aligned}
$$

We also add a linear constraint to this problem, representing a specific height to width ratio of the cross section

$$
u_{2} \leqslant c_{1} u_{1}
$$

This optimization problem is solved using our in-house tool developed in Matlab. The optimization method used is the Sequential Quadratic Programming algorithm (SQP), a gradient based algorithm that can handle constrained nonlinear programming problems.

The Sequential Quadratic Programming algorithm works by solving in an iterative manner a series of quadratic programming sub-problems which are based on the expansion about the current design point of both the objective and the constraint functions using the Taylor series. Although the full description of this algorithm is out of the scope of this paper, a detailed description of it can be found in Venkataraman (2002).

The SQP algorithm is implemented within the optimization function fmincon of Matlab and, in turn, this function is coded in our tool, which invokes the constraint functions (which are not explicit functions of the design variables $u_{1}, u_{2}$ ), and the objective function in every iteration.

A flowchart of the optimization approach is presented in Fig. 2. The design variables $\{u\}$ are changed throughout the optimization process while keeping the values of the applied bending and torsional moments. Thus, as geometry changes, the applied stresses are updated in every iteration as well as the equivalent stress calculated according to the multiaxial high cycle fatigue criterion. The latter is then compared against the permissible value of $\bar{\beta}$ that is $t_{-1}$. New values of $u_{1}, u_{2}$ are set and the iterative process continues until the objective function, i.e., the cross sectional area achieves the conditions of convergence and the solution still satisfies the fatigue constraints.

\section{Numerical examples}

As a numerical example of the size optimization approach presented here, we use a rectangular cross-section beam model as the one depicted in Fig. 1, under biaxial in-phase and out-of-phase loads. 


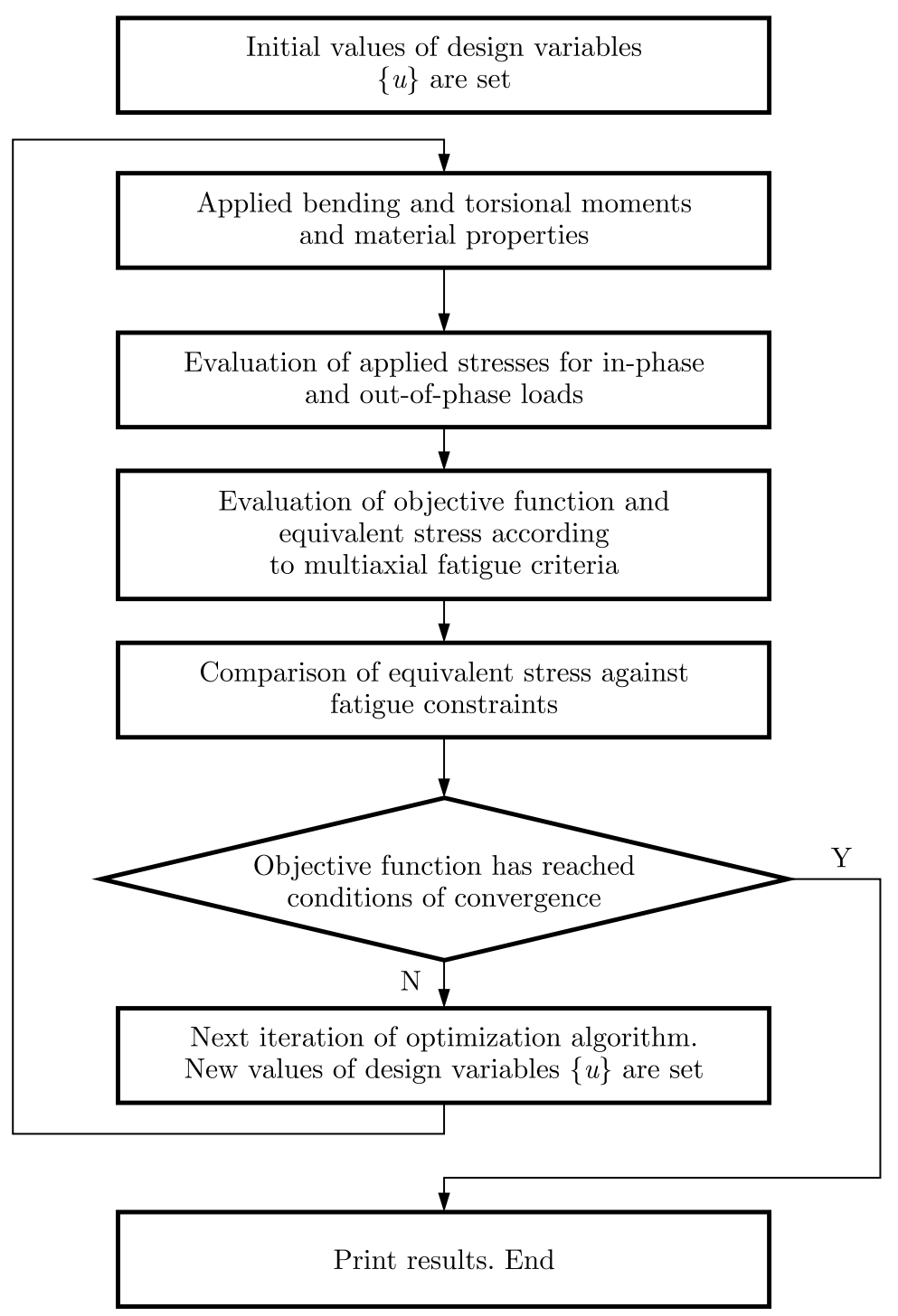

Fig. 2. Flowchart of the implemented optimization approach

We define six loading cases acting over this model representing cyclic, fully reversible, bending and torsional moments. These combinations appear in Table 2. For the first three loading cases, bending and torsional moments are applied in phase, therefore $\phi$, the phase angle, equals zero. For the last three loading cases, bending and torsional moments are applied out of phase, and $\phi$ equals $90^{\circ}$. Examples of the resulting stress histories are seen in Fig. 3.

Table 2. Loading cases acting over the rectangular cross-section model. Applied bending moment $M_{b, a}$, applied torsional moment $M_{t, a}$, phase angle $\phi$

\begin{tabular}{|c|c|c|c|}
\hline $\begin{array}{c}\text { Loading } \\
\text { case }\end{array}$ & $\begin{array}{c}M_{b, a} \\
{[\mathrm{Nm}]}\end{array}$ & $\begin{array}{c}M_{t, a} \\
{[\mathrm{Nm}]}\end{array}$ & $\begin{array}{c}\phi \\
{[\mathrm{deg}]}\end{array}$ \\
\hline \hline 1 & 20 & 10 & 0 \\
\hline 2 & 25 & 12.5 & 0 \\
\hline 3 & 30 & 15 & 0 \\
\hline 4 & 20 & 10 & 90 \\
\hline 5 & 25 & 12.5 & 90 \\
\hline 6 & 30 & 15 & 90 \\
\hline
\end{tabular}


(a)

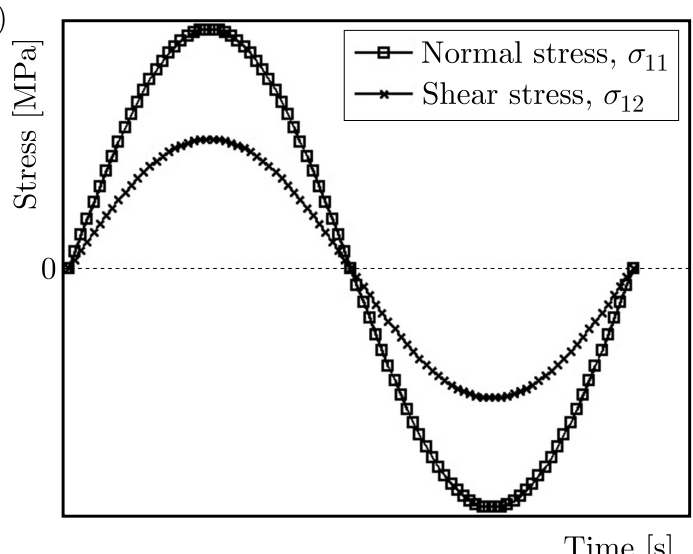

(b)

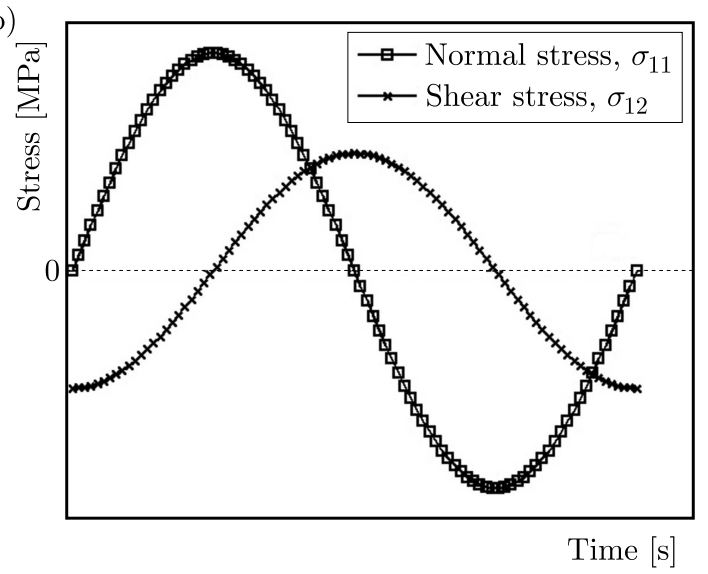

Fig. 3. Stress histories acting over the model: (a) in-phase loads, (b) out-of-phase loads

The material employed in the analyses is hard steel. It has the following properties relevant for fatigue design: ultimate strength $S_{u}=680 \mathrm{MPa}$, fatigue limit in fully reversed bending $f_{-1}=313.9 \mathrm{MPa}$, fatigue limit in fully reversed torsion $t_{-1}=196.2 \mathrm{MPa}$. Data are taken from Nishihara and Kawamoto reported in (Papadopoulos et al., 1997).

As stated earlier, the objective of the optimization is to minimize the area of the rectangular cross section member for each loading case and for three different height to width ratios of the section $(1.50,1.75$, and 2.00). This is accomplished while keeping the values of the applied bending and torsional moments, and also while keeping the fatigue endurance of the model. The initial values of the design variables are set as: $u_{1}=8 \mathrm{~mm}, u_{2}=10 \mathrm{~mm}$ for all loading cases. This point is selected from within the feasible region, which we explain in detail in the next Section.

\section{Results and discussion}

The optimum values of area of the rectangular cross-section members have been calculated for each loading case of Table 2, using the Dang Van and Vu-Halm-Nadot multiaxial high cycle fatigue criteria as constraints. This means finding the minimum cross sectional area that will withstand the applied loads, and will do it with an equivalent stress below the fatigue limit in fully reversed torsion, or in other words, will be able to resist infinite life.

These results are shown in tables 3,4 and 5 for three different height to width ratios of the section, respectively. We will explain our results throughout an example. Let us refer to loading case six for which: $M_{b, a}=30 \mathrm{Nm}, M_{t, a}=15 \mathrm{Nm}, \phi=90^{\circ}$. The initial values of the design variables selected from within the feasible region are: $u_{1}=8 \mathrm{~mm}, u_{2}=10 \mathrm{~mm}$. The height to width ratio is 1.50, and the Dang Van fatigue criterion is used. After application of the size optimization, the optimum value of area found is $60.29 \mathrm{~mm}^{2}$. For the same loading conditions but using a $H / W$ ratio of 1.75 , the optimum value is $57.27 \mathrm{~mm}^{2}$. Finally, for a $H / W$ ratio of 2.00 , the optimum value is $54.78 \mathrm{~mm}^{2}$.

We use the feasible solution space for the same loading case as a graphical representation of the optimization problem. It is shown in Figs. 4 and 5 for both fatigue criteria, respectively.

The points on any curve of this diagram have the same value. Therefore, we observe contour curves of a constant area representing the objective function, to decrease from the upper right corner to the down left corner of the picture. Three dotted lines represent the values of the height to width ratio of the cross section. The remaining solid curve represents the value of the fatigue limit for each criterion. The initial values of the design variables are selected from within the feasible region, i.e., the region beneath the specific line of $H / W$ ratio and above the curve 
Table 3. Optimum values of the area for $1.0 \cdot 10^{6}$ cycles. Height to width ratio: 1.50

\begin{tabular}{|c|c|c|c|c|c|}
\hline Loading & $M_{b, a}$ & $M_{t, a}$ & $\phi$ & \multicolumn{2}{|c|}{$A_{\text {optim }}\left[\mathrm{mm}^{2}\right]$} \\
\cline { 5 - 6 } case & {$[\mathrm{Nm}]$} & {$[\mathrm{Nm}]$} & {$[\mathrm{deg}]$} & Dang Van & VHN \\
\hline \hline 1 & 20 & 10 & 0 & 54.70 & 52.70 \\
\hline 2 & 25 & 12.5 & 0 & 63.47 & 61.15 \\
\hline 3 & 30 & 15 & 0 & 71.68 & 69.05 \\
\hline 4 & 20 & 10 & 90 & 46.01 & 50.49 \\
\hline 5 & 25 & 12.5 & 90 & 53.39 & 58.58 \\
\hline 6 & 30 & 15 & 90 & 60.29 & 66.16 \\
\hline
\end{tabular}

Table 4. Optimum values of the area for $1.0 \cdot 10^{6}$ cycles. Height to width ratio: 1.75

\begin{tabular}{|c|c|c|c|c|c|}
\hline Loading & $M_{b, a}$ & $M_{t, a}$ & $\phi$ & \multicolumn{2}{|c|}{$A_{\text {optim }}\left[\mathrm{mm}^{2}\right]$} \\
\cline { 5 - 6 } case & {$[\mathrm{Nm}]$} & {$[\mathrm{Nm}]$} & {$[\mathrm{deg}]$} & Dang Van & VHN \\
\hline \hline 1 & 20 & 10 & 0 & 52.98 & 50.99 \\
\hline 2 & 25 & 12.5 & 0 & 61.48 & 59.17 \\
\hline 3 & 30 & 15 & 0 & 69.43 & 66.82 \\
\hline 4 & 20 & 10 & 90 & 43.71 & 48.49 \\
\hline 5 & 25 & 12.5 & 90 & 50.72 & 56.27 \\
\hline 6 & 30 & 15 & 90 & 57.27 & 63.54 \\
\hline
\end{tabular}

Table 5. Optimum values of the area for $1.0 \cdot 10^{6}$ cycles. Height to width ratio: 2.00

\begin{tabular}{|c|c|c|c|c|c|}
\hline Loading & $M_{b, a}$ & $M_{t, a}$ & $\phi$ & \multicolumn{2}{|c|}{$A_{\text {optim }}\left[\mathrm{mm}^{2}\right]$} \\
\cline { 5 - 6 } & {$[\mathrm{Nm}]$} & {$[\mathrm{Nm}]$} & {$[\mathrm{deg}]$} & Dang Van & VHN \\
\hline \hline 1 & 20 & 10 & 0 & 51.78 & 49.77 \\
\hline 2 & 25 & 12.5 & 0 & 60.08 & 57.76 \\
\hline 3 & 30 & 15 & 0 & 67.85 & 65.22 \\
\hline 4 & 20 & 10 & 90 & 41.80 & 46.95 \\
\hline 5 & 25 & 12.5 & 90 & 48.51 & 54.49 \\
\hline 6 & 30 & 15 & 90 & 54.78 & 61.53 \\
\hline
\end{tabular}

of fatigue endurance. The optimum values are at the intersection of a $H / W$ ratio line and the fatigue curve, see Figs. 4 and 5. They correspond to those reported in Tables 3-5.

In Figs. 6a and 6b, the convergence histories for loading case 6 using both criteria are shown. As it can be seen, after the initial value of the objective function is set, the Sequential Quadratic Programming algorithm quickly converges to the minimum point within just four iterations.

In order to establish a comparative base for the results obtained and to check their effectiveness, we have arrived at similar optimum values of the objective function by means of fatigue criteria based on two different methods, i.e., multi-scale and stress-invariants.

Furthermore, the results from Tables 3-5 and Figs. 4 and 5 show that amongst the optimum values, less amount of material is needed to withstand the applied loads when the $H / W$ ratio is increased, see Table 6. Finally, with regard to the fatigue criteria included as constraints, the $\mathrm{Vu}$-Halm-Nadot criterion has an advantage of faster computing times.

\section{Conclusion}

Little research has been devoted to the problem of size optimization of structural members subject to non-proportional cyclic stresses. Therefore, we present an approach aimed at minimizing 


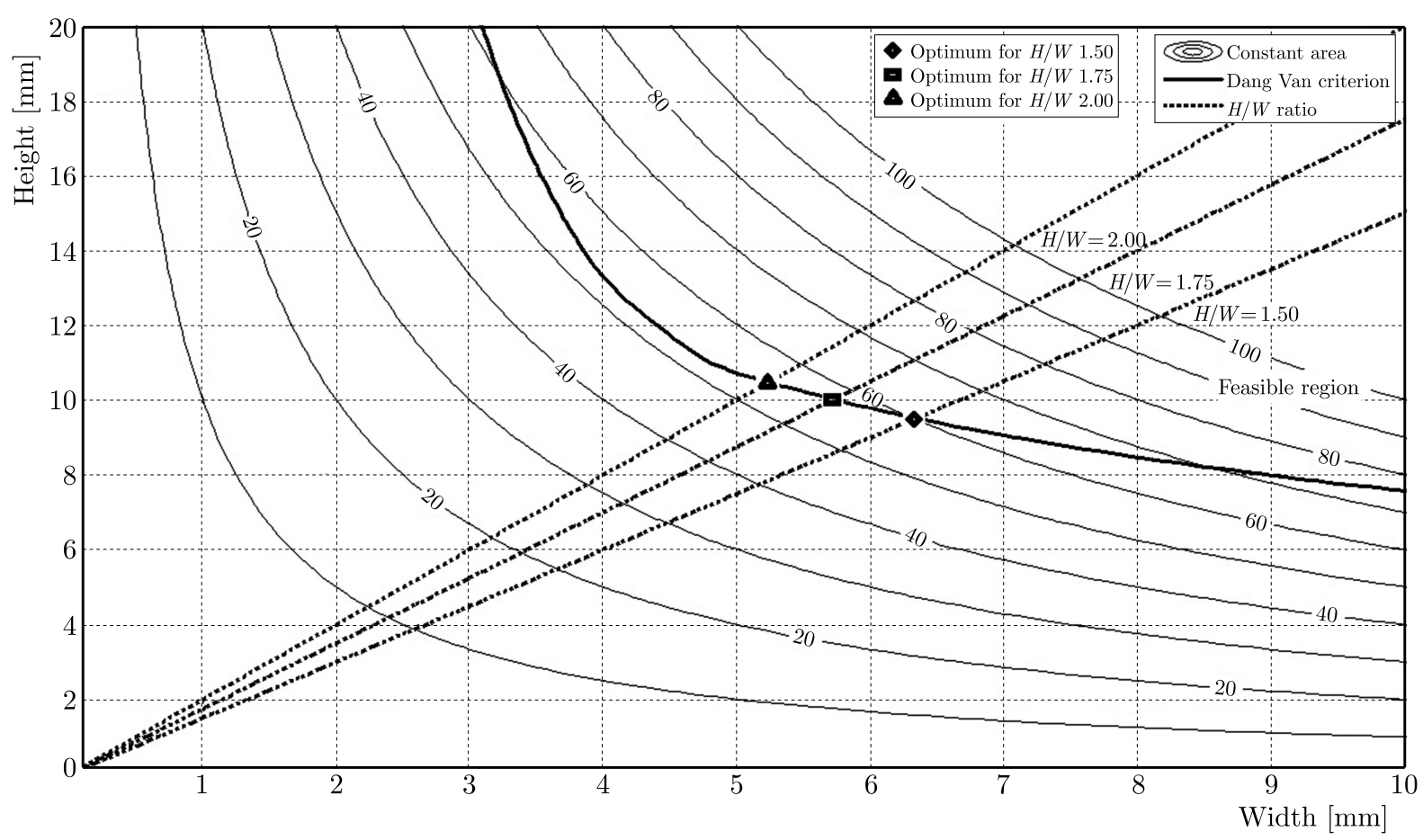

Fig. 4. Feasible solution space using the Dang Van criterion as a constraint, loading case 6. Contour curves of a constant area in $\mathrm{mm}^{2}$

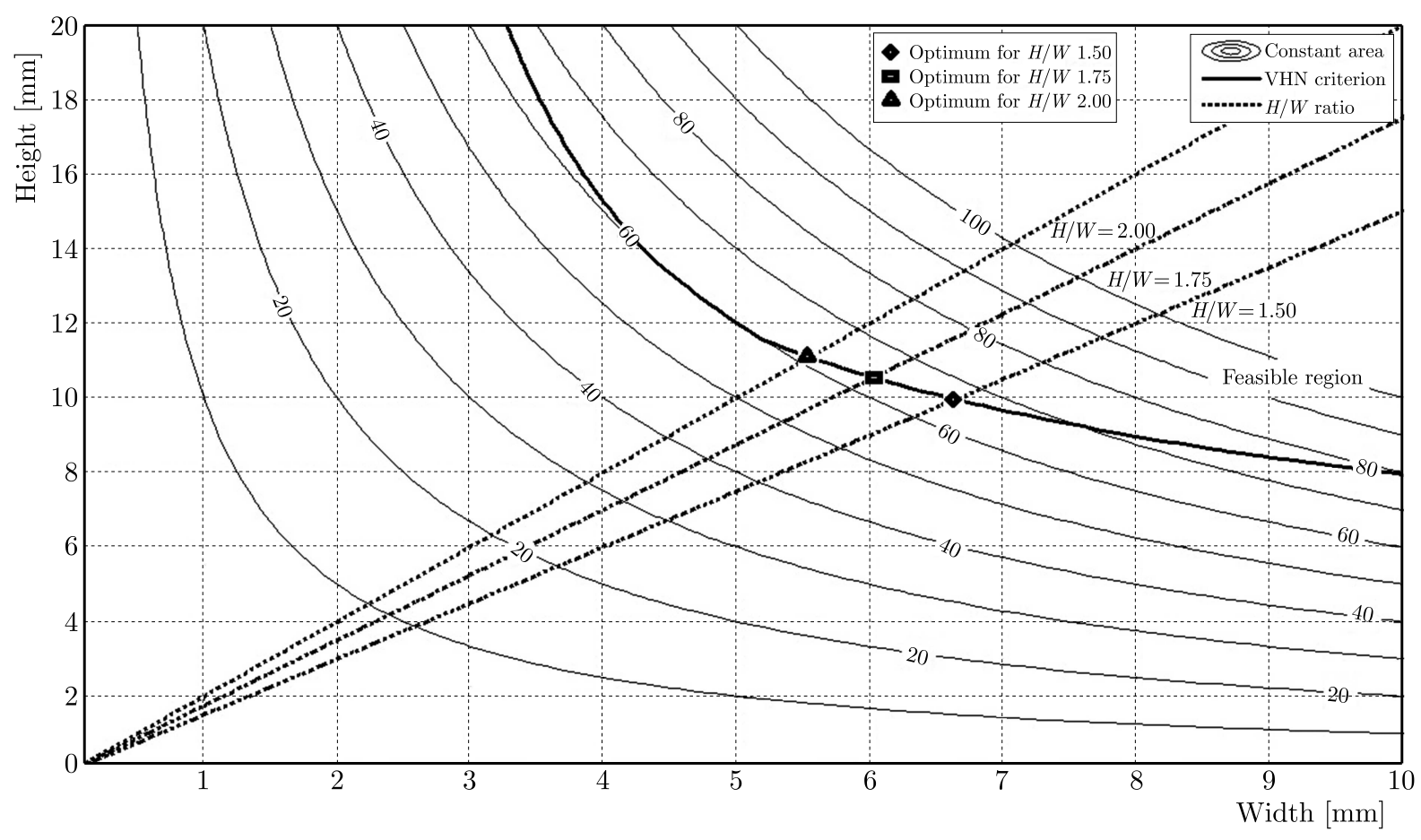

Fig. 5. Feasible solution space using the Vu-Halm-Nadot criterion as a constraint, loading case 6 .

Contour curves of a constant area in $\mathrm{mm}^{2}$

the area of rectangular cross-section members under multiaxial in-phase and out-of-phase cyclic loadings while retaining their fatigue endurance.

This approach is based on the use of an in-house developed tool, in which two multiaxial high cycle fatigue criteria have been included as constraints, i.e., the Dang Van and Vu-Halm-Nadot criteria, coded as nonlinear constraints within the fmincon optimization function in Matlab. 
(a)

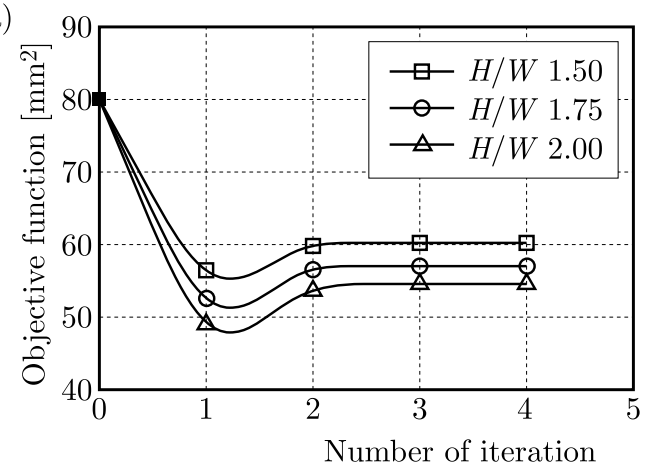

(b)

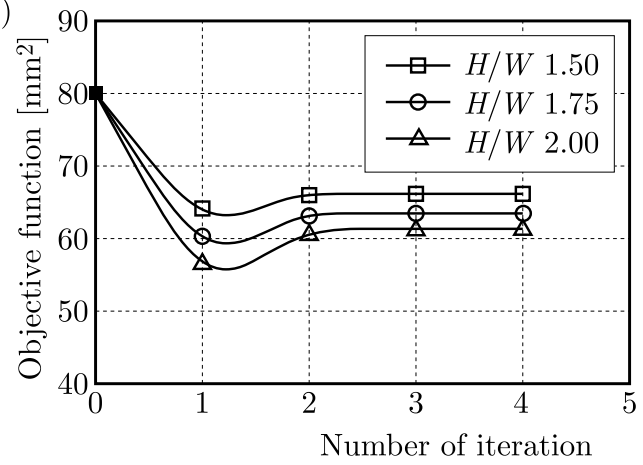

Fig. 6. Convergence diagram, loading case 6. Initial value of the objective function in all cases: $80 \mathrm{~mm}^{2}$. Fatigue criterion: (a) Dang Van, (b) Vu-Halm-Nadot

Table 6. Reduction of optimum values of the area as the height to width ratio increases, for both criteria

\begin{tabular}{|c|c|c|c|}
\hline $\begin{array}{c}\text { Loading } \\
\text { case }\end{array}$ & $\begin{array}{c}\text { Increase of } \\
\text { the height } \\
\text { to width } \\
\text { ratio }\end{array}$ & $\begin{array}{c}\text { Reduction } \\
\text { of area [\%] } \\
\text { Dang Van } \\
\text { criterion }\end{array}$ & $\begin{array}{c}\text { Reduction } \\
\text { of area [\%] } \\
\text { VHN } \\
\text { criterion }\end{array}$ \\
\hline \hline $1,2,3$ & 1.50 to 1.75 & 3.14 & 3.24 \\
\hline $4,5,6$ & 1.50 to 1.75 & 5.01 & 3.95 \\
\hline $1,2,3$ & 1.75 to 2.00 & 2.28 & 2.39 \\
\hline $4,5,6$ & 1.75 to 2.00 & 4.35 & 3.17 \\
\hline
\end{tabular}

In the numerical examples given as the reference, optimum values of the area are obtained for each loading case and for three values of the height to width ratio of the cross section. If we consider mass of an element to be proportional to its cross-sectional area, minimizing this area would mean a reduction of mass.

The novelty of the approach lies in the inclusion of multiaxial high cycle fatigue criteria as constraints for structural optimization problems capable of handling non-proportional loads, and the obtainment of the feasible solution space, including these fatigue constraints, which is a visual aid for verifying the viability of the solution for each loading case. The results of the applied approach are encouraging, since it can be useful for experimental work in which rectangular cross-section specimens are used, or as a base for methods focused on size optimization using the Sequential Quadratic Programming algorithm.

Acknowledgements

This research was supported by the Mexican Science and Technology National Council (CONACYT).

\section{References}

1. Andjelić N., Milosević-Mitić V., 2012, Optimum design of thin-walled I-beam subjected to stress constraint, Journal of Theoretical and Applied Mechanics, 50, 4, 987-999

2. Baptista R., Claudio R.A., Reis L., Guelho I., Freitas M., Madeira J.F.A., 2014, Design optimization of cruciform specimens for biaxial fatigue loading, Frattura ed Integritá Strutturale, 30, $118-126$

3. Boresi A.P., 2002, Advanced Mechanics of Materials, 6th edition, Wiley

4. Christensen P., Klarbring A., 2009, An Introduction to Structural Optimization, Springer 
5. Dang Van K., Griveau B., Message O., 1989, On a new multiaxial fatigue limit criterion: theory and applications, [In:] Biaxial and Multiaxial Fatigue, EGF 3, M.W. Brown and K.J. Miller (Edit.), Mechanical Engineering Publications, London, 479-496

6. Gasiak G., Robak G., 2010, Simulation of fatigue life of constructional steels with the mixed modes I and III loading, Fatigue and Fracture of Engineering Materials and Structures, 34, 389-402

7. Ghelichi R., Bernasconi A., Guagliano M., 2011, Geometrical optimization of notches under multiaxial fatigue loading, International Journal of Fatigue, 33, 985-991

8. Holmberg E., Torstenfelt B., Klarbring A., 2014, Fatigue constrained topology optimization, Structural Multidisciplinary Optimization, 50, 207-219

9. Jeong S.H., Choi D.H., Yoon G.H., 2015, Fatigue and static failure considerations using a topology optimization method, Applied Mathematical Modelling, 39, 1137-1162

10. MATLAB. R2013b documentation. The MathWorks, Inc.; 2013

11. MrzygŁód M., 2010, Two-stage optimization method with fatigue constraints for thin-walled structures, Journal of Theoretical and Applied Mechanics, 48, 3, 567-578

12. MrzygŁód M., Zieliński A.P., 2006, Numerical implementation of multiaxial high-cycle fatigue criterion to structural optimization, Journal of Theoretical and Applied Mechanics, 44, 3, 691-712

13. Papadopoulos I.V., Davoli P., Gorla C., Filippini M., Bernasconi A., 1997, A comparative study of multiaxial high-cycle fatigue criteria for metals, International Journal of Fatigue, 19, 3, 219-235

14. Rozumek D., Marciniak Z., Macha E., 2010, Fatigue life of specimens with round and rectangular cross-sections under out-of-phase bending and torsional loading, The Ninth International Conference on Multiaxial Fatigue and Fracture (ICMFF9), Parma (Italy), 75-85

15. Timoshenko S., Goodier J.N., 1951, Theory of Elasticity, 2nd edition, McGraw-Hill

16. Venkataraman P., 2002, Applied Optimization with MATLAB Programming, Wiley

17. Vu Q.H., Halm D., Nadot Y., 2010, Multiaxial fatigue criterion for complex loading based on stress invariants, International Journal of Fatigue, 32, 1004-1014

Manuscript received November 10, 2015; accepted for print November 24, 2016 